Part of Journal of Research of the National Bureau of Standards, Volume 23, July 1939

\title{
X-RAY DIFFRACTION PATTERNS OF HEVEA, MANIHOT, AND OTHER RUBBERS
}

\author{
By George L. Clark, ${ }^{1}$ Siegfried T. Gross, ${ }^{2}$ and W. Harold Smith
}

\section{ABSTRACT}

When rubber from Hevea brasiliensis is stretched quickly and exposed to a beam of X-rays, a crystal fiber diffraction pattern is obtained. During previous work, done jointly by the National Bureau of Standards and the University of Illinois on sol and gel fractions of this rubber, no pattern was produced by the stretched sol fraction. With the stretched gel fraction, however, the pattern was sharp and intense. Kubber from Manihot glaziovii also may be separated into sol and gel fractions, and in recent work they, too, have been stretched and examined by X-rays. With the stretched Manihot sol, a few interferences were obtained, but many more resulted with the stretched gel. When crystallized by "freezing" at low temperatures for 24 hours, the interferences from the gel again outnumbered those from the sol. The X-ray measurements of Manihot rubber agree with those of Hevea rubber and indicate that the same structure exists in each. Rubbers obtained from latices of Funtumia elastica, Cryptostegia grandiflora, and Castilla elastica were also examined. Their structures, too, were like that of Hevea rubber, and the similarity confirms earlier observations made when X-ray technique was less highly developed. In crystallized specimens, the crystals melted within the range of temperatures previously observed with Hevea rubber.

In earlier work a large spacing was observed in a specimen of unstretched Hevea gel rubber. This spacing has been observed also in a new specimen of stretched Hevea gel rubber, together with a second spacing approximately twice as large.

\section{CONTENTS}

I. Introduction

II. Purification of the rubbers

III. Melting temperatures of frozen specimens

IV. X-ray patterns

\section{INTRODUCTION}

The preparation of ether sol and gel fractions of rubber from Hevea brasiliensis was described in a previous publication. ${ }^{3}$ When fractions prepared by that method are stretched, the sol fraction does not produce the X-ray diffraction pattern characteristic of a crystal fiber, ${ }^{4}$ but such a pattern is formed by stretched total rubber. The stretched gel fraction produces a pattern at approximately 100percent elongation, and at 200-percent elongation the pattern is quite sharp and intense. Ether sol and gel fractions have not been reported to occur in all crude rubbers. They may be obtained, however, from the rubber of Manihot glaziovii, a tree closely related

1 Professor, University of Illinois.

Instructor, University of Illinois.

W. Harold Smith, Charles Proffer Saylor, and Henry J. Wing, BS J. Research 10, 479 (1933) RP544.

- George L. Clark, Enno Wolthuis, and W. Harold Smith, J. Research NBS 19, 479 (1937) RP1039. 
to Hevea brasiliensis. The ether sol and gel of Manihot rubber, when stretched, have been examined by X-rays for comparison with the behavior of the corresponding fractions of Hevea rubber.

Some years ago it was reported by Hauser ${ }^{5}$ that 20 rubbers from different sources were found by X-ray examination to be alike. Since that time X-ray measurements have been refined. Three rubbers, other than Hevea, were examined by modern equipment to check Hauser's observations. In our earlier work a large spacing was noted in a specimen of unstretched Hevea gel rubber, and, for comparison with it, a new specimen of this fraction has been investigated in the stretched condition.

\section{PURIFICATION OF THE RUBBERS}

The rubbers used in the present work were obtained as latices from the nursery of the Department of Agriculture at Coconut Grove, Fla., through the courtesy of the Office of Plant Exploration and Introduction. They represented Hevea brasiliensis, Manihot glaziovii, Funtumia elastica, Cryptostegia grandiflora, and Castilla elastica. Their purification was undertaken by a method which had been developed with Hevea latex. As originally described, it was used successfully with Castilla latex, and the resulting rubber contained 0.04 percent of nitrogen. With the other latices some modification of the original method was necessary, because natural latices have differing characteristics.

Manihot glaziovii, the rubber of which is known in commerce as Ceara or Manicoba, belongs to the same family, Euphorbiaceae, as Hevea brasiliensis and has some marked resemblances to it. For example, the trees of each species may be subjected to suitable repeated tappings without a diminishing yield of latex. The latex of Manihot glaziovii, however, is less stable than that of Hevea brasiliensis, and may coagulate during tapping. ${ }^{6}$ The Manihot latex as received always was coagulated. The loose coagulum was washed with successive portions of distilled water to remove serum constituents, then cut into pieces about $1 \mathrm{~mm}^{3}$ and again washed with water. As much protein as possible was removed by digestion with a solution of trypsin, but since the solution could not penetrate the coagulated rubber, some protein remained. The residual rubber was washed with a 1-percent solution of sodium hydroxide at room temperature, and then with distilled water until all alkali was removed. The extracted total rubber contained 0.09 percent of nitrogen (determined by the Kjeldahl method). Part of the nitrogen is doubtless accounted for by protein, which does not affect the diffraction pattern of stretched rubber. Finally, the rubber was extracted with acetone for 18 hours in an apparatus through which nitrogen was passed, and then extracted with ether to separate the sol form from the gel form. As an additional precaution against oxidation, some of the natural antioxidant extracted from pale crepe Hevea rubber was dissolved in the acetone and in the ether.

\footnotetext{
5 E. A. Hauser, Naturwissenschaften 15, 100 (1927).

- Although Manihot latex contains spherical particles like those of Hevea latex, most of the rubber consists of tiny rods, which, according to Zimmermann (A. Zimmerman, Der Manihot Kautschuk, G. Fischer, Jena, 1913) are less than $1 \mu$ wide and approximately $10 \mu$ long. Freundlich and Hauser (H. Freundlich and E. A. Hauser, Kolloid- Z. 36 (Supplement), 29 (1925)) found no adsorption layer around the rods, and its absence probably accounts for the instability of the latex. They noted that the rods of rubber consist of very tough, tacky, homogeneous material.
} 
The latex of Funtumia elastica contains an effective stabilizing agent which inhibits coagulation. After treatment with trypsin, the latex was dialyzed to remove as many of the impurities as possible, and coagulated with acetone. The rubber was dissolved in benzene, the impurities were allowed to settle, and from the clear solution in benzene the rubber was precipitated with acetone. When benzene, acetone, and moisture were removed, the rubber contained 0.07 percent of nitrogen.

When the latex of Cryptostegia grandiflora was treated with trypsin, a black solid material slowly collected on the surface. It was removed and discarded. Subsequently, the latex was dialyzed, and most of the residual colored material was removed, but the rubber slowly coagulated. The coagulum was collected, washed with hot water, dried, and as much of it as possible was dissolved in benzene. When the impurities had settled, the dissolved rubber was precipitated by acetone. It contained 0.02 percent of nitrogen. When treated with benzene or with ethyl ether, this rubber did not dissolve completely. Some undissolved gel and impurities remained.

\section{MELTING TEMPERATURES OF FROZEN SPECIMENS}

The melting temperatures of crystalline material in specimens of Hevea rubber, crystallized by "freezing" at suitable low temperatures, have already been reported in this journal. ${ }^{7}$ The temperatures within which melting occurred were not the same for all the specimens, but all melted between $-5^{\circ}$ and $+16^{\circ} \mathrm{C}$. This range was similar to that previously observed with discrete crystals prepared from ethereal solutions. For comparison with these observations, the melting ranges were determined of frozen specimens prepared from the other latices used in this work. As was observed with Hevea rubber, the temperatures of melting with different specimens of the same rubber were not alike, but specimens of all the rubbers melted within the range $-5^{\circ}$ to $+16^{\circ} \mathrm{C}$.

\section{X-RAY PATTERNS}

Except when otherwise indicated, the technique used for X-ray measurement is the same as that which was described in a previous publication. ${ }^{8}$

The specimens of Manihot sol and gel with which patterns were obtained were stretched quickly, almost to the breaking point. In figure $1(A)$ that of the sol is reproduced and in figure $1(B)$ that of the gel. Each pattern was made with filtered $K \alpha$ radiation from copper. The pattern of the sol definitely shows less perfect fibering. A monochromatic fiber pattern of stretched Manihot gel is shown in figure $1(C)$. The monochromatic beam was obtained by diffracting the $\mathrm{X}$ radiation from copper from the ground surface of a crystal of pentaery thritol, according to the technique described by I. Fankuchen. ${ }^{9}$

A list of the more important measurements obtained with stretched Manihot gel is given in table 1. The deviations of spacing from the corresponding measurements with Hevea gel rubber are doubtless caused by an uncertainty in estimating the center of the stretched sample. The distance from specimen to film was about $6.9 \mathrm{~cm}$.

${ }^{7}$ W. Harold Smith and Charles Proffer Saylor, J. Research NBS 21, 257 (1938) RP1129.

$8 \mathrm{~J}$. Research NBS 19, 479 (1937) RP1039.

I. Fankuchen, Nature 139, 193-94 (1937). 


\section{TABLE 1.-Measurements from stretched Manihot gel rubber}

[In the tables, $d$ is the distance between the set of planes making an angle $\theta$ with the incident beam, $R$ is the radius of the diffraction spot or ring as measured on a flat film, and the letter $i$ indicates an intense interference]



Specimens of unstretched Manihot sol and gel were kept simultaneously at $-20^{\circ} \mathrm{C}$ for 24 hours. Two interferences were observed with the sol fraction, corresponding to spacings of $6.18 \mathrm{~A}$ and $4.25 \mathrm{~A}$.

The pattern shown in figure $1(D)$ is that of the frozen Manihot gel. It was made in a low-temperature camera very similar to that used by Wolthuis, ${ }^{10}$ but with less distance, approximately $3 \mathrm{~cm}$, between specimen and film. The exact distance was determined by calibration with sodium chloride. Unfiltered $K \alpha$ radiation from copper was used. Measurements of the pattern are given in table 2 with the computed interplanar distances, which are compared with those previously found for frozen Hevea gel rubber. ${ }^{11}$

TABLE 2.-Measurements from frozen Manihot gel rubber and those previously obtained from frozen Hevea gel rubber

\begin{tabular}{|c|c|c|c|}
\hline \multicolumn{3}{|l|}{ Manihot gel } & Hevea gel \\
\hline Lines & Radius & $d$ & $d$ \\
\hline${ }^{1}$ & $\begin{array}{l}c m \\
0.67 \\
.86 \\
1.04 \\
1.18 \\
1.25\end{array}$ & $\begin{array}{l}A \\
6.30 \\
5.02 \\
4.21 \\
3.76 \\
3.58\end{array}$ & $\begin{aligned} & A \\
& 6.20 \\
& 4.99 \\
& 4.20 \\
& 3.74 \\
& 3.48\end{aligned}$ \\
\hline${ }^{6}{ }^{6}{ }^{8}$ & $\begin{array}{l}\text { 1. } 31 \\
1.37 \\
1.42 \\
1.53 \\
1.61\end{array}$ & $\begin{array}{l}\text { 3. } 44 \\
\text { 3. } 31 \\
\text { 3. } 21 \\
2.02 \\
2.89\end{array}$ & $\begin{array}{r}3.02 \\
2.82\end{array}$ \\
\hline 112 & $\begin{array}{l}2.58 \\
2.69\end{array}$ & $\begin{array}{l}2.07 \\
2.02\end{array}$ & 2.07 \\
\hline
\end{tabular}

Hauser ${ }^{12}$ examined with X-rays rubbers from 20 different sources. The rubbers represented different botanical classifications and came from different geographical origins. The lattice spacings and intensitives were the same in all. Since that work was done the methods of producing X-ray diffraction patterns have been much improved and, at present, measurements of rubber by different investigators agree within a few hundredths of an angstrom unit.

10 J. Research NBS 19, 479 (1937) RP1039.

12 E. A. Hauser, Naturwissenschaften 15, 100 (1927). 


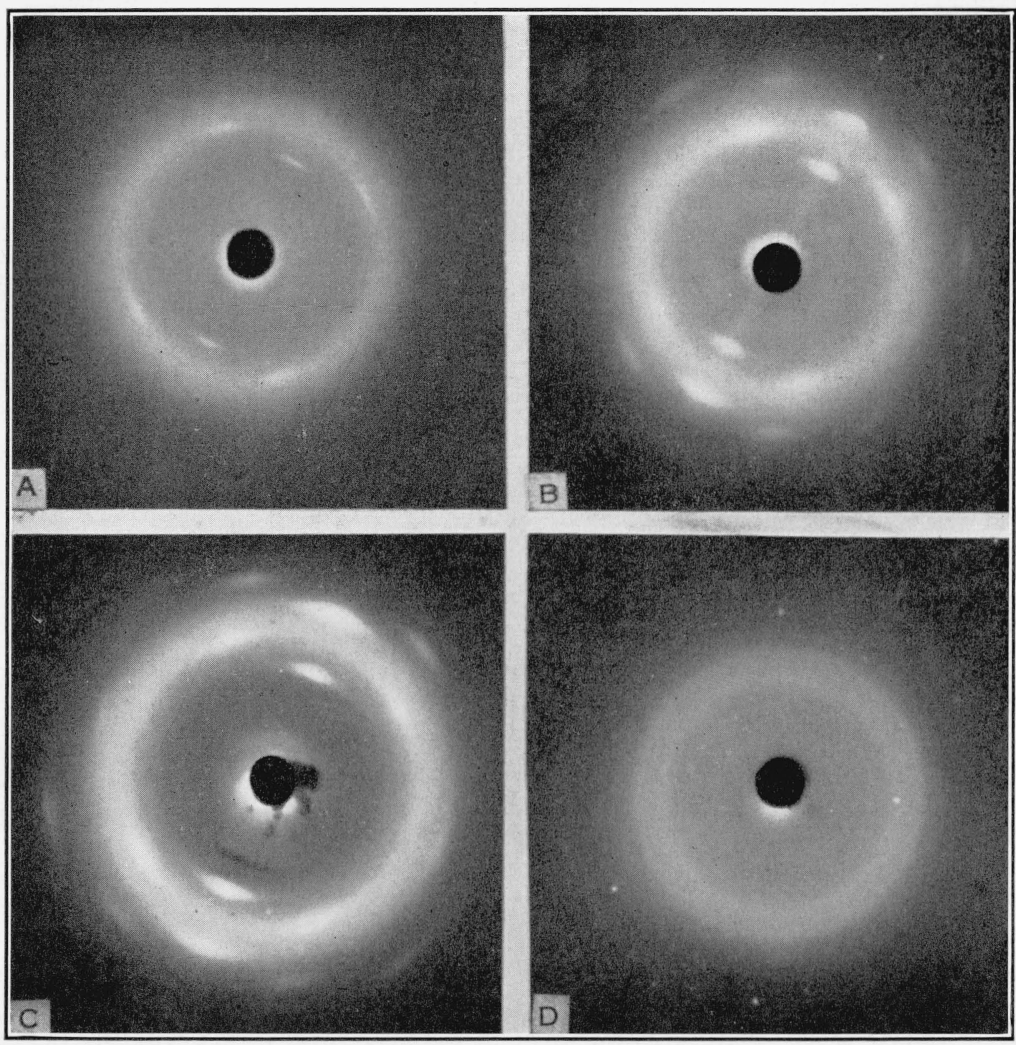

Figure 1.-X-ray diffraction patterns.

$A$ and $B$ were obtained with stretched Manihot sol and gel rubbers, respectively, made with filtered $K \alpha$ radiation from copper; $C$ is a monochromatic fiber pattern of stretched Manihot gel; and $D$ is a pattern of frozen Manihot gel.' 




FIGURE 2.-X-ray diffraction fiber pattern of stretched Hevea gel rubber, showing two large interplanar spacings. 
X-ray measurements were also made on frozen specimens of Funtumia elastica, Cryptostegia grandiflora, and Castilla elastica. The values of interferences obtained with each rubber agreed and were the same as those reported by Lotmar and Meyer, ${ }^{13}$ by Clark, Wolthuis, and Smith, ${ }^{14}$ and by Barnes, ${ }^{15}$ within $0.05 \mathrm{~A}$. These results confirm the earlier observations of Hauser.

In a previous publication ${ }^{16}$ there was an illustration of a long spacing of $54 \mathrm{~A}$, which was observed in a specimen of unstretched ether gel of Hevea rubber. The spacing was absent from the corresponding sol. The gel from which the specimen was taken was stored in contact with ether and in darkness at temperatures between $2^{\circ}$ and $6^{\circ} \mathrm{C}$ to suppress oxidation. It was hoped that during storage, any residual soluble material would be dissolved, leaving undissolved the molecules of greatest weight. Under the conditions of storage, however, less than 2 percent of the gel became soluble. After 18 months a specimen was freed of ether and it was examined by X-rays. The diffraction pattern of the stretched material, using filtered $K_{\alpha}$ radiation from copper, is reproduced in figure 2. The same long spacing appears at the position observed before, $54 \mathrm{~A}$. The longspacing arcs on the equator of the pattern are clearly visible. In addition there is faint but definite evidence of a second still longer spacing which corresponds to about $108 \mathrm{~A}$. On the film this ring appears as a darkened area around the central spot.

The material used in this work was obtained from the Department of Agriculture through L. G. Polhamus, Bureau of Plant Industry, Washington, D. C., and H. F. Loomis, U. S. Plant Introduction Garden, Coconut Grove, Fla. Their cooperation is appreciated.

Washington, March 14, 1939.

13 W. Lotmar and K. H. Meyer, Monatsh. 69, 115 (1936).

$14 \mathrm{~J}$. Research NBS 19, 479 (1937) RP1039.

${ }_{15}$ William H. Barnes, Can. J. Research 15, 156 (1937).

${ }^{16}$ See footnote 14. 